\title{
Business Process Modelling Languages in Designing Integrated Information System for Supply Chain Management
}

\author{
Mohsen Mohammadi, Muriati Bt. Mukhtar \\ Information Science and Technology, Universiti Kebangsaan Malaysia, Bangi, 43600, Malaysia \\ E-mail:mohammadi.m54@gmail.com,mm@ftsm.ukm.my
}

\begin{abstract}
A business process model is very germane to the formation of an appropriate information system. For a marked infusion of business processes in the supply chain, the status quo regarding the processes must be totally understood and well secured. Business activities and sequence have to be well kept and properly coordinated by predicting business procedures process from diverse views. This study examines seven BPMLs Data Flow Diagram (DFD), Unified Modelling Language (UML), Business Process Modelling Notation(BPMN), Event Driven Process Chain (EPC), IDEF, Petri Net, and Role Activity Diagram (RAD). The submissions of this study are the subject of the Business Process Modelling Languages (BPMLs) in developing an integrated dissemination mechanism and classification of modelling tools.
\end{abstract}

Keywords—Business Process Modelling Languages; Information system; Supply Chain; AS-IS analysis; TO-BE design.

\section{INTRODUCTION}

Supply chain management refers to the coordination of vital business activities ranging from the customers to the actual manufacturers and provider of other factors such as services and enlightenment programmes that will enhance the productivity of the business [1]. There are some merits attached to the use of this approach, they include (a) securing a competitive opportunity; (b) bringing down of cost of services and (c) attaining a more stabilised partnership and organisation among supply chain partners. The incorporation of information system (IS) approach is a barrier to many business outfits; this is so because supply chain practitioners are made up of autonomous mechanisms which may not interact with one another. In addition to this is the complicated nature of the information systems presently in use whose templates for messages, sources of information and interfaces are not flexible and dynamic. Subsequently, the incorporation of its workability with respect to a supply chain may likely be an ambiguous exercise.

The use of incorporation as a technique is premised on the availability of various possible mechanisms and methods such as message brokers, adapters and ebXML to integrate systems. These mechanisms attain homogeneity at various instances i.e. information, correspondence, object, interface and/or programme level [2]. A business process model represents a condition for finding appropriate dissemination procedures. Explanations on commercial ventures are necessary in discovering the proper channel to propagate and find a base for the venture. Mathematical expressions for ventures also serve as prerequisites when searching for technical expertise during the formative stages of the dissemination exercise [3]. To have a successful incorporation of ventures in the supply chain, there must be a total grasp and full stock-taking of the processes presently in use (AS-IS models) [4]. The process of finding a mathematical expression and the estimation of various available situations for (TO-BE models) for enhancement remains the motivators of the venture's resuscitation mechanism [5]. The association between commercial ventures procedure and dissemination system is explicitly examined in section 2. The BPMLs are discussed in section 3 and their categorization is discussed in section 4 .

\section{BUSINESS PROCESS AND INFORMATION SYSTEM}

Supply chain management (SCM) refers to an infusion of coordination of business interconnectivity, dissemination of correspondence and personnel's interaction [2]. A procedure is an amalgamation of inter-related or autonomous processes that are used jointly to achieve a target via the conversion of a concept into an end-product (goods or services) for the benefit of a third party (customer) making use of labour, equipment and strategies [6]. Entrepreneurship could be carried out by hired labour upon supervision by competent personnel or through the aid of dissemination mechanisms. In addition, there are also some activities that could be 
achieved through self-programmed operation via electronic devices devoid of human participation [7]. In this regards, activities and information processes are remotely coordinated. BP and IS are inter-related as there exists between input and output interfaces for individual step and/or interaction with IS. For example, what exists between BP output-IS input medium is utilized to get data present in the BP sets to carry out the equivalent functions in the IS. Consequently, the reverse of this condition is utilized to bring out the difference between the output of IS and the units of BP. From Figure 1, it can be observed that there is response to any of the input on all the processes within the system [8].

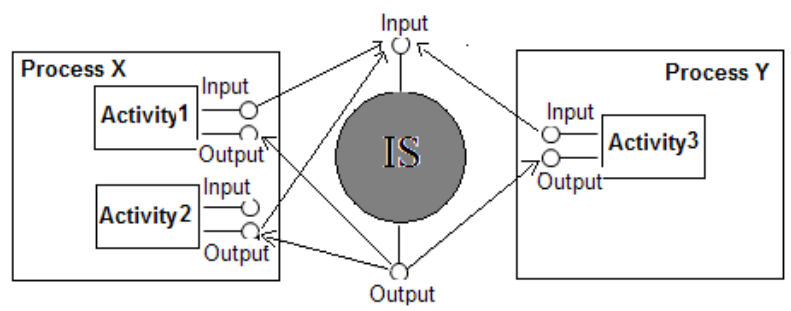

Figure 1: BP and IS relationship [8]

\section{AN OVERVIEW OF BUSINESS PROCESS MODELLING LANGUAGES}

A business procedure is made up of several activities carried out in an orderly manner within an enterprise under close monitoring and guided supervision [7]. Carefully researched mathematical analytical expressions deduced from rigorous scientific exercises have become very useful in accomplishing these tasks. These also involve the use of scientific principles and theories for the evaluation, estimation and resuscitation of several factors aimed at the sustenance of the inherent activities within the system [10]. Some of the frequently used mathematical analytical methods are: Petri-Net [14], Data Flow Diagram (DFD) [24],[25], Integrated definition(IDEF) [26], Event-driven Process Chain (EPC) [27], extended Event-driven Process Chain (eEPC) [28],[29],Role Activity diagram(RAD)[ 13], Unified Modelling Language (UML) [30],[31] and Business Process Modelling Notation (BPMN) [32].

\section{A. Petri-Net}

Petri Nets are used for the prediction of values of workflows. A Petri Net is a specific plot made up of two dissimilar orientations, positions and phases. Position stands for the likely conditions of the system while phases refer to activities responsible for different physical condition [18].Petri nets do not constitute a predicting entity per se, due to their nature as a tool for system's prediction. Nevertheless, among the common system predicting mechanisms, it is known to be the most popular for prediction of business process because of its inherent ability as [14]. Normal Petri nets are plots of systems[12]. Figure 2 shows a typical average Petri net.

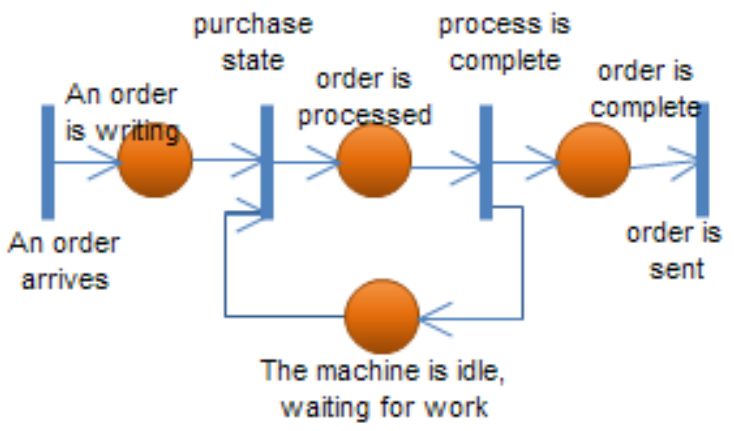

Figure 2. Petri net example [15]

\section{B. Data Flow Diagram (DFD)}

The monitoring of systems is the main function of DFDs. The tasks include keeping in view the inflow, outflow and movement of data within and without the system. In this regards, they can be likened to flowcharts with the only difference in the subject under consideration (DFDs deliberate on rather than processes and conditioning). Though, DFDs are widely known for prediction of data, there are some constraints in their activities. Due to its high emphasis on data, it has no basis with which work flexibility, personnel, occurrences, and other factors could be compared [12].

\section{CLASSIFICATION THE BPML}

Table 1 shows the three categories of BPMLs as: workflow model, dataflow model, and dynamic model model. This division may consider the predicting tools on the basis of how they are put to use. The aim of workflow model is to showcase the flexibility in the work outlay with inherent pattern, recurring, opposite and circumstantial attributes of the IS. The function of the dataflow model is to display the flexibility of the dataflow while being operated upon. These two models can accommodate the basic flows of the IS, but they are not equipped with the ability to neither actualize an imaginary phenomenon nor evaluate it [11]. However, the dynamic model which is designed for this purpose has the capability of analysing and standardizing a system. These models (Dynamic models) can actually display IS by making use of plotted notation and carrying out a robust simulation.

TABLE I

CLASSIFICATION OF THE MODELING TOLLS [11],[17],[18]

\begin{tabular}{|c|c|}
\hline Classification & Modelling tools \\
\hline $\begin{array}{c}\text { Workflow } \\
\text { model }\end{array}$ & $\begin{array}{c}\text { IDEF(IDEF3), EPC, RAD, } \\
\text { UML(activity diagram), BPMN }\end{array}$ \\
\hline $\begin{array}{c}\text { Data flow } \\
\text { mode }\end{array}$ & DFD, UML(interaction diagram) \\
\hline $\begin{array}{c}\text { Dynamic } \\
\text { model }\end{array}$ & $\begin{array}{c}\text { IDEF(IDEF2), RAD, UML(state } \\
\text { diagram, activity diagram, } \\
\text { collaboration diagram, sequence } \\
\text { diagram), BPMN, Petri net }\end{array}$ \\
\hline
\end{tabular}


Table 2 shows the function and the origin of successive BPML. These BPMLs concentrate on either the detailed account of or the initiation of processes save for the EPCs. The origin of all BPMLs except Petri Nets is in the aspect of science and technology that makes use of sets of instructions specifically developed to be deciphered by a conditioned self-operating device. The methods were designed when the terms currently in use nowadays were yet to be proposed, precisely in the sixties, though the phenomenon were adequately dealt with then [18].

TABLE II

PURPOSE AND SOURCE DOMAIN OF MODELING TOOLS [17],[18]

\begin{tabular}{|c|c|}
\hline Source domain & Modelling tools \\
\hline $\begin{array}{c}\text { System } \\
\text { Engineering }\end{array}$ & Petri net \\
\hline $\begin{array}{c}\text { Process } \\
\text { Engineering }\end{array}$ & DFD, EPC, eEPC, BPMN \\
\hline $\begin{array}{c}\text { Software } \\
\text { Engineering }\end{array}$ & IDEF, RAD, UML \\
\hline
\end{tabular}

\section{Integrated definition(IDEF)}

The fundamental idea of IDEF is premised upon wellestablished tools of investigation that have been confirmed to be highly efficient in performance [16]. The IDEF structure comprises of autonomous methods with the most visible being the IDEF0 (function modelling), IDEF1x (data modelling), and IDEF3 (process description capture). Some disadvantages are associated with IDEF0 and this make the approach inappropriate for certain analysis. Incidentally, IDEF0 equations are rigid pictorial representation having no mention of instance. The development of IDEF3 was to make up for some of the defects of IDEF0 mathematical expressions. IDEF3 defines processes as methodical procedure of actions aimed at achieving a target [12]. An IDEF0 configuration is shown in Figure 3 while Figure 4 displays an example of an IDEF0.

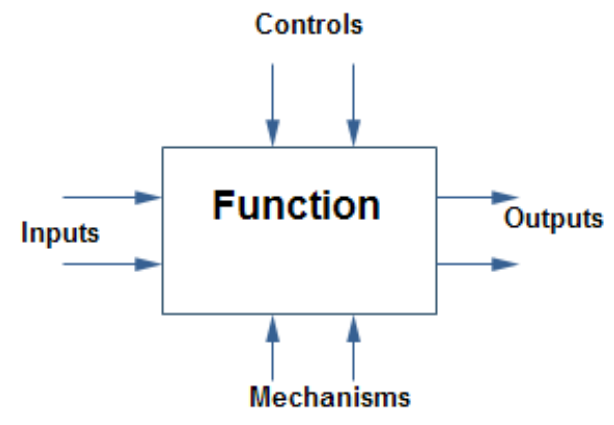

Figure 3. IDEF0 notation

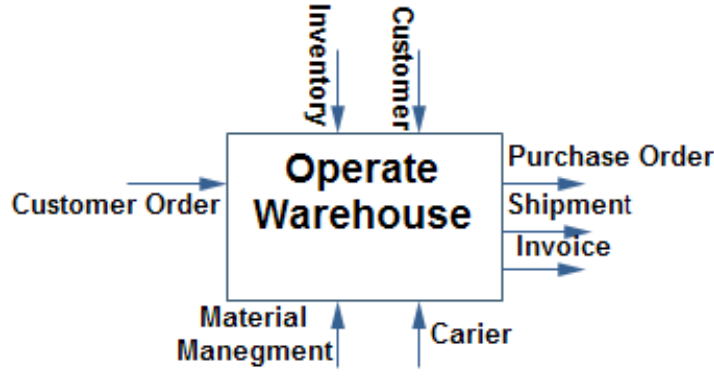

Figure 4. IDEF0 example [ 12]

\section{Event-driven Process Chain (EPC)}

This method was designed to predict business activities that would be easily comprehended by those involved in the process. The fundamental units of EPC are occurrence and situations. While occurrence predicts the achievable efforts of a venture's procedure, situations are formed by operating on the occurrences or by external factors [18].

\section{E. Role Activity diagram(RAD)}

RAD is believed to have had its origin from the prediction of coordination.[34]. Currently, it is utilized for predicting business activities [36]. It illustrates functions, operations and relationships as well as external occurrences.

\section{F. $\quad$ Unified Modelling Language (UML)}

This method has been lately used' as a recognized indicator for prediction and communication of events [33]. This role is a direct consequence of the methods prowess as an accurate and hence an highly efficient predicting and analytical tool [19]. This method entails the use of three prediction approaches vis-à-vis: use case models, fixed models and flexible models. The first class of models refers to the needs of the system from the perception of the users, while the second category of models is range related and showcases the association between elements in a system which encompasses generalisation, additional and interactive relationships. .The third category of models describes the performance and attitude of the system [20].

\section{G. Business Process Modelling Notation (BPMN)}

This is a very robust method used to predict events applicable to all condition irrespective of levels, end users, by-standers and stakeholders as well [21,22]. This method evolved from the strict vigilance and schedule of OMG (Object Management Group) and it identifies four classes of entities viz-a-viz [21]: flow objects, connecting objects, swim lanes and artefacts. BPMN developed for converting ventures procedures to a set of instructions that are understandable and interpretable by a designated apparatus, in this case the Business Process Modelling Language, (BPML) [35].

\section{CONCLUSIONS}

Stakeholders in a supply chain (SC) must identify with a mutual guideline aimed at effecting a vast incorporation of long lasting and dependable SC systems. This effort must work in favor of the Supply Chain activities regardless of 
status or category. One of the very special categories happens to be infused information system. These systems supply the technological know-how needed for the instantaneous conceptualization of fresh ideas into what will result in the latest state of the art products and also for the conversion of the previously used concepts to objects of basis, comparison and criticism with regards to the new products thus maintaining a balance necessary for the sustenance of the system. Efforts on business processes can be accomplished via the information systems instantaneously. Therefore, a complete grasp of these activities must be painstakingly taken into consideration. The use of more than one method of prediction techniques for the purpose of generating series of data and evidences in support of a business activity regardless of from which and whose point of view will definitely and positively aid a comprehensive appraisal and assessment of such a venture in diverse ways and under different conditions and this will greatly assist the prospective stakeholders in taking a quick and most often favorable decision. Hence, for a complex system, an example of which is a supply chain, business oriented activities must be totally appraised, assessed and properly coordinated using inputs from different conditions and perceptions.

\section{REFERENCES}

[1] D.M. Lambert, M.C. Cooper, Issues in supply chain management, Industrial Marketing Management ,vol. 29 , pp. 65-83, 2000

[2] M. Themistocleous, Z. Irani and P. D. Love, "Evaluating the integration of supply chain information systems: A case stud ," European Journal of Operational Research, vol. 159, pp. 393-405, 2004.

[3] P. Trkman, M. S temberger, J. Jaklic and A. Groznik , "Process approach to supply chain integration ," Supply Chain Management: An International Journal Vo. 12 , No. 2, pp.116-128, 2007 .

[4] A. Lockamy and K.McCormack, "The development of a supply chain management process maturity model using the concepts of business process orientation ,", Supply Chain Management: An International Journal, Vol. 9 No. 4 ,

[5] B. Vuksic, V., Indihar Stemberger, M., Jaklic, J. and A.

Kovacic, "Assessment of e-business transformation using simulation modeling,", Vol. 78, No. 12, pp. 731-44, 2002.

[6] D. Zhang, "Web services composition for process management in ebusiness ,", Journal of Computer Information Systems, Vol. 45 No. 2, pp. 83-91, 2005.

[7] M. Weske ,Business ProcessManagement Concepts, Languages, Architectures, Springer-Verlag Berlin Heidelberg , 2007.

[8] R. J. Paul and A. Serrano , "Simulation for Business Process and Information System design, "Proceedings of the 2003 Winter Simulation Conference, 2003.

[9] P. Soffer and Y. Wand, "Goal-Driven Multi-Process Analysis,", Journalof Association for Information Systems, Vo. 8, Issue 3, Article 2, pp. 175-202, March 2007.

[10] M.. Hammer, and J. Champy, Reengineering the Corporation - A manifesto for Business Revolution, London, Nicholas Brealey Publishing, 1994.

[11] S. Huang, D. C. Yen, Y. Hung, Y. Zhou and J. Shiuan Hua , "A business process gap detecting mechanism between information system process flow and internal control flow ," , Decision Support Systems, Vol.. 47 , pp. 436-454, 2009.

[12] G. GIAGLIS, "A Taxonomy of Business Process Modeling and Information Systems Modeling Techniques ," Kluwer Academic Publishers, Boston. Manufactured in The Netherlands, The International Journal of Flexible Manufacturing Systems, Vol. 13 , pp 209-228, 2001.

[13] T. Huckvale, and M.Ould, "Process Modeling-Who, What and How: Role Activity Diagramming," in: Business Process Change: Concepts, Methods and Technologies, V. Grover and W. J. Kettinger (Eds.), Idea Group Publishing, Harrisburg, PA, pp. 330-349,1995.
[14] W. Reising, S. Muchnick and P.Schnupp, (Eds.), A Primer in Petri Net Design, Springer-Verlag, Berlin, 1992.

[15] J. L.Peterson, , Petri Net Theory and the Modeling of Systems, Prentice-Hall, Englewood Cliffs, NJ,1981.

[16] Zhou1, G. Rong, "Study of Supply Chain Monitoring System Based on IDEF Method ", IEEE. 978-1-4244-7330-4/10, 2010.

[17] H. Shena, B. Wallb, M. Zarembab, Y. Chen and J.Browne, "Integration of business modelling methods for enterprise information system analysis and user requirements gathering ", Computers in Industry, Vol. 54, PP. 307-323, 2004.

[18] B. List, B. Korherr, "An Evaluation of Conceptual Business Process Modelling Languages ", SAC'06, April 23-27, 2006, Dijon, France. ACM 1-59593-108-2/06/0004, 2006.

[19] M.R. Bastos, A. D. Dubugras , "Extending UML Activity Diagram for Workflow Modeling in Production Systems ",Proceedings of the 35 th Annual Hawaii International Conference on System Sciences (HICSS-35.02), IEEE ,0-7695-1435-9/02, ,2002 .

[20] Cheol-Han Kim, R.H. Weston, A. Hodgson and Kyung-Huy Lee, "Thecomplementary use of IDEF and UML modelling approaches", Computers in Industry, Vol. 50, pp. 35-56, 2003

[21] M. Juric and K. Pant, Business Process Driven SOA using BPMN and BPEL, Packt Publishing, 1st Edition, 2008.

[22] "Business process modelling notation specification", OMG,http://www.bpmn.org/Documents/OMG\%20Final\% 20Adopted\%20BPMN\%201-0\%20Spec\%2006-02-01.pdf, 2006. Accessed on March 8, 2009

[23] M.JABER, Y.BADR and F. BIENNIER "Distributed Information System for the Supply Chain Integration ", IEEE, 0-7803-9521, 2006.

[24] O. Turetke, D. Schuff, R. Sharda, T.T. Ow, Supporting systems analysis and design through fisheye views, Communications of The ACM 47,Vol. 9, PP. 72-77, 2004.

[25] J.L. Witten, L.D. Bentley, K.C. Dittman, System Analysis \& Design Methods 7th,McGrawHill, 2005.

[26] C. Badica, A. Badica, V. Litoiu, A new formal IDEF-based modelling of businessprocesses, Proceedings of the First Balkan Conference in Informatics, 2003.

[27] Y.C. Yu,W.H. Chen, K.P. Liu, Integration of EPC and a modularized colored Petri-Net through events for agile manufacturing cell control, Proceedings of the 2004 IEEE, International Conference on Networking, Sensing \& Control, 2004.

[28] Y.C. Juan, C.O. Yang, Systematic approach for the gap analysis of business processes, International Journal of Production Research Vol. 42,PP. 1325-1364, 2004.

[29] A.W. Scheer, Aris - Modellierungsmethoden, Metamodelle, Anwendungen,Spinger, 2001.

[30] G. Booch, J. Rumbaugh, I. Jacobson, The Unified Software Development Process, Addison-Wesley, 1999.

[31] T. Schattkowsky,UML 2.0-overviewand perspectives in SoC design, Proceedings of the Design, Automation and Test in Europe Conference and Exhibition, pp. 823-833, 2005.

[32] S.A. White, Business Process Modeling Notation (BPMN) Version 1.0, 2004 http://BPMI.org., Last accessed: 20 June 2011.

[33] C.L. Ang, L.P. Khoo, R.K.L. Gay, IDEF: a comprehensive modelling methodology for development of manufacturing enterprise system, International Journal of Production Research,Vol.37, PP. 3839-3858, 1999.

[34] Holt, A., Ramsey, R. and Grimes, J. Coordinating System Technology

as the Basis for a Programming Environment. Electrical Communication, Vol. 57, No. 4, pp. 307-314, 1983.

[35] Business Process Management Initiative: Business Process Modeling Language. Specification Version 1.0, No.13, 2002, http://www.bpmn.org/, Last accessed: 20 May 2011.

[36] Ould, M. Business Processes - Modelling and Analysis for Reengineering and Improvement. John Wiley \& Sons, 1995. 